\title{
Decreased lung function in 7-year-old children with early-life organophosphate exposure
}

\author{
Rachel Raanan, ${ }^{1}$ John R Balmes, ${ }^{2,3}$ Kim G Harley, ${ }^{1}$ Robert B Gunier, \\ Sheryl Magzamen, ${ }^{4}$ Asa Bradman, ${ }^{1}$ Brenda Eskenazi ${ }^{1}$
}

\begin{abstract}
- Additional material is published online only. To view please visit the journal online (http://dx.doi.org/10.1136/ thoraxjn-2014-206622)

${ }^{1}$ Center for Environmental Research and Children's Health (CERCH), School of Public Health, University of California, Berkeley, California, USA 'Division of Environmental Health Sciences, School of Public Health, University of California, Berkeley, California, USA

${ }^{3}$ Divison of Occupational and Environmental Medicine, University of California, San Francisco, California, USA ${ }^{4}$ Department of Environmental and Radiological Health Sciences, Colorado State University, Fort Collins, Colorado, USA
\end{abstract}

\section{Correspondence to}

Dr Rachel Raanan, Center for Environmental Research and Children's Health (CERCH), UC Berkeley School of Public Health, 1995 University Avenue, Suite 265, Berkeley, CA 94704, USA;

rachelraananrr@gmail.com

Received 26 November 2014 Revised 15 September 2015 Accepted 29 September 2015 Published Online First

3 December 2015

\section{ABSTRACT}

Background Organophosphate pesticides are heavily used in agriculture, and adverse associations with respiratory health in occupational settings have been reported. However, most of the evidence comes from studies where there were no biomarkers of exposure and no objective outcome measurement. Non-occupational chronic effects among residents living in agricultural communities are less well described.

Objective To evaluate associations between early-life organophosphate exposure and lung function of children living in an agricultural community.

Methods Participants were 279 children from the Center for the Health Assessment of Mothers and Children of Salinas (CHAMACOS) longitudinal birth cohort. The area under the curve for organophosphate exposure was determined by urinary diethyl and dimethyl dialkylphosphate metabolites of organophosphate pesticides, which were measured five times during childhood (6-60 months). Spirometry was performed at age 7 years. Regression models controlled for maternal smoking during pregnancy, season of birth, particulate matter concentrations with aerodynamic diameter $\leq 2.5 \mu \mathrm{m}\left(\mathrm{PM}_{2.5}\right)$, breast feeding duration, mould and pets at home, distance of home from a highway, food insecurity, maternal education, season of spirometry, sex, height and technician.

Results Childhood diethyl, dimethyl and total dialkylphosphate concentrations were associated with significant decreases in lung function at age 7. Specifically, we found lower $\mathrm{FEV}_{1},(\mathrm{~L} / \mathrm{s})(B=-0.16,95 \%$ $\mathrm{Cl}-0.30$ to $-0.02, \mathrm{p}=0.03)$ and FVC (L) $(B=-0.17$, $95 \% \mathrm{Cl}-0.34$ to $0.01, p=0.06)$ per 10 -fold increase of total dialkylphosphate levels.

Conclusions Early-life organophosphate exposure as assessed by dialkylphosphate concentrations was adversely associated with 7-year-old children's lung function.

\section{INTRODUCTION}

The aetiology of chronic paediatric respiratory disease, such as asthma, is not fully understood..$^{1-3}$ Some environmental agents such as air pollution and tobacco smoke have been reported to be adversely associated with respiratory symptoms and impaired lung function, ${ }^{12}$ and others such as pesticides and household chemicals have been implicated. $^{23}$

Although most residential uses of organophosphate pesticides (OPs) were phased out in the mid-2000s, they are still heavily applied in US agriculture with 15 million kilograms used in 2007

\section{Key messages}

What is the key question?

- Does prolonged early-life exposure to organophosphate pesticides (OPs), the most commonly used pesticide in agriculture, have an adverse effect on paediatric lung function?

What is the bottom line?

- This study presents the first scientific evidence that non-occupational early-life exposure to OPs (ie, chronic low-level exposure to OPs at environmental relevant concentrations) is associated with decreased pulmonary function and may have a restrictive effect on children's lungs.

\section{Why read on?}

- The causes for much paediatric respiratory disease are not fully understood; we present a new link between pesticides that are heavily used in agriculture and paediatric respiratory health that may be important to clinicians and researchers.

(36\% of total insecticide use). ${ }^{45}$ This is reflected in the widespread detection of OP metabolitesdialkyl phosphate metabolites (DAPs) - in urine samples from the general US population. ${ }^{6}$

OPs can affect respiratory function by inhibition of acetylcholinesterase (AChE). ${ }^{7}$ Additionally, animal studies have reported that at doses below those that can cause AChE inhibition, OPs can induce airway hyper-reactivity. ${ }^{8}$

Occupational investigations have reported adverse associations between pesticides and respiratory health, including rhinitis, asthma, chronic bronchitis, cough and wheeze. ${ }^{9}{ }^{10}$ A comparison of 89 pesticide sprayers with 25 controls found an inverse association between self-reported long-term pesticide exposure and forced expiratory flow at $25-75 \% \quad\left(\mathrm{FEF}_{25-75}\right)$, and between short-term exposure as measured by serum cholinesterase and $\mathrm{FEV}_{1}{ }^{11}$ Working for the agricultural sector was inversely associated with $\mathrm{FEV}_{1}$ (in ex-smokers) in 13253 subjects in the European Community Respiratory Health Survey study. ${ }^{12}$ Reported occupational exposure to unspecified pesticides was inversely associated with $\mathrm{FEV}_{1}$ and $\mathrm{FEV}_{1} / \mathrm{FVC}$ in 11851 subjects in the LifeLines cohort. $^{13}$ 
A reduction of $\mathrm{FEV}_{1}$ and $\mathrm{FVC}$ was demonstrated among 25 Sri Lankan farmers occupationally exposed to OPs. ${ }^{14}$ In a nonoccupational survey of 213 households in South Africa an adverse association between wheeze and use of insecticide in the home was reported, ${ }^{15}$ and in random household samples in rural Ethiopia, wheeze and the use of malathion (an OP pesticide) were associated. ${ }^{16}$

Reported paediatric respiratory symptoms were associated in a few studies with early-life, non-specific pesticide exposure in non-longitudinal designs. ${ }^{17}{ }^{18}$ A study based on 14065 participants aged $\leq 18$ years from the National Health and Nutrition Examination Survey reported ambiguous results-an association between wheezing and dry cough and pesticide use in the kitchen and dining room, but no association with overall domestic use. ${ }^{19}$

We previously reported an association between respiratory symptoms at age 5 and 7 and early-life exposure to OP pesticides as assessed by urinary DAPs measured during pregnancy and childhood. ${ }^{20}$ These children were participants in the Center for the Health Assessment of Mothers and Children of Salinas (CHAMACOS) study, a longitudinal birth cohort investigating the health effects of environmental exposures on pregnant women and children living in the Salinas Valley, California. ${ }^{21}$ In this study, we examine the association of urinary DAP concentrations in pregnant women and their children in early childhood with spirometry at 7 years of age. Here we present the first report ${ }^{3}$ on an association between exposure to OP pesticides, as measured by DAPs and pulmonary lung function tests in children.

\section{METHODS}

\section{Study setting and design}

Pregnant mothers were recruited to the CHAMACOS study during October 1999-October 2000. Women were eligible for the study if they were $\geq 18$ years of age, at $<20$ weeks gestation and were planning to deliver at the county hospital, English or Spanish speaking and Medi-Cal (a state health insurance programme based on economic need) eligible.

\section{Participants}

Six hundred and one pregnant mothers were recruited to the cohort; 526 delivered live-born surviving singletons. Detailed methods are described elsewhere. ${ }^{21}$ Research protocols were approved by the University of California, Berkeley, Committee for the Protection of Human Subjects. Written informed consent was obtained from the mothers. Child assent was obtained at age 7.

We performed spirometry on 279 of these children at age 7 . $\mathrm{FEV}_{1}, \mathrm{FVC}$ and $\mathrm{FEF}_{25-75}$ were available for 279,250 and 250 children, respectively. Of the children for whom we obtained $\mathrm{FEV}_{1}$, FVC and $\mathrm{FEF}_{25-75}$, we had prenatal urinary DAPs for 275, 246 and 246 mothers and early childhood DAPs for 231, 206 and 206 children, respectively.

\section{Maternal interviews}

Information on covariates was obtained by maternal interviews, home visits conducted by trained personnel when the children were 6 and 12 months old and abstraction of prenatal and delivery records by a registered nurse. Mothers were also asked whether the child had been prescribed any medication for asthma or wheezing/whistling, or tightness in the chest. Women were interviewed twice during pregnancy (mean $\pm \mathrm{SD}=13.4$ $\pm 4.7,26.5 \pm 2.6$ weeks' gestation), after delivery and when their children were $0.5,1,2,3.5,5$ and 7 years old.

\section{Spirometry}

A clinical examination was performed when the child was 7 , including maximum expiratory flow volume tests and height and weight measurements. Identical dry-seal spirometers were used in the study. Routine calibration was performed every morning. Tests were performed by bilingual and bicultural technicians specifically trained for the study. Three identical EasyOne spirometers were used by two technicians; $92 \%$ of the tests were performed by the same technician. Quality control was supervised by two physicians experienced in paediatric spirometry.

Each child performed a maximum of eight expiratory manoeuvres and up to three best acceptable tests were kept by the spirometric software. Each acceptable blow lasted at least $3 \mathrm{~s}$. The children were coached to blow until the EasyOne signalled that the test had ended. All attempts were coached. Quality control was also achieved by verifying that the child did not lean forward; air did not leak out of the side; the child took enough air in and took a deep breath right from the beginning; blew enough air out; did not stop blowing too soon; and took a big smooth breath. All manoeuvres were reviewed again and verified by the two physicians to assure quality control. See online supplementary methods for more details.

\section{Pesticide exposure: DAP metabolites}

Six urinary DAP metabolites of OP pesticides comprised three diethyl (DEs: diethylphosphate, diethylthiophosphate and diethyldithiophosphate) and three dimethyl (DMs: dimethylphosphate, dimethylthiophosphate and dimethyldithiophosphate) phosphates were measured twice during pregnancy $(\mathrm{M} \pm \mathrm{SD}=13.4 \pm 4.7$ and $26.5 \pm 2.6$ weeks, respectively) and five times during childhood when children were approximately 0.5 , $1,2,3.5$ and 5 years old. Maternal and child urine samples were stored at $-80^{\circ} \mathrm{C}$. Non-specific DAP metabolites were summed on a molar basis to calculate total DEs, total DMs and total DAPs. ${ }^{22}$ Analyses were conducted by the Division of Laboratory Science at the Centers for Disease Control and Prevention using gas chromatography-tandem mass spectrometry and quantified using isotope dilution calibration. ${ }^{23}$

\section{Data analysis}

For prenatal analysis, we examined diethyl phosphates (DEs), dimethyl phosphates (DMs) and total DAP concentrations $(\mathrm{nmol} / \mathrm{L})$ from maternal urinary samples collected at the first and second halves of pregnancy (0-20, 21-40 weeks' gestation), as well as the average of these two measurements. For postnatal analysis, we calculated the area under the curve (AUC) from the five urinary metabolite measurements conducted during childhood using the trapezoidal method. ${ }^{20}$ For each time interval, we calculated the time-weighted average concentration by multiplication of time between measurements (years) by the average of the two measured concentrations. Time-weighted averages from each time interval were summed to calculate the AUC. Forty-three children were excluded from the AUC analysis owing to lack of DAP measurements at either 0.5 or 5 years, or lack of more than one measurement at ages 1,2 and 3.5 years. If a child had only one missing DAP measurement at 1,2 , or 3.5 years $(n=5)$, we imputed the mean of the two closest measures. DAP concentrations (in the first and second halves of pregnancy; the arithmetic average of the two pregnancy measurements; and the AUC of the childhood measurements) were $\log 10$ transformed. DAP concentrations were corrected for urinary dilution in maternal samples by dividing the DAP 
concentration by urinary specific gravity and in child samples by dividing by urinary creatinine.

We used general linear models (GLMs) to estimate the associations of prenatal and early childhood DAPs with $\mathrm{FEV}_{1}, \mathrm{FVC}$, $\mathrm{FEV}_{1} / \mathrm{FVC}$ and $\mathrm{FEF}_{25-75}$. We estimated the associations between the highest spirometric measures for children who had one, two or three manoeuvres and for children who had at least two manoeuvres (ie, two or three manoeuvres). Covariates were selected based on directed acyclic graphs. We controlled for child's sex, height, child's age (months) and age squared, pets at home (at ages 5 and 7), household food insecurity score during the previous 12 months (at age 7; measured by using the US Household Food Security Instrument, Spanish version ${ }^{24}$ ), maternal education, season of spirometry (winter/spring/summer/autumn) and technician. We also controlled for covariates previously identified in our analysis of DAPs and respiratory symptoms ${ }^{20}$ (tables 3 and 4): maternal smoking during pregnancy, season of birth (mould/ wet/pollen/dry), mean daily particulate matter concentrations with aerodynamic diameter $\leq 2.5 \mu \mathrm{m}\left(\mathrm{PM}_{2.5}\right)$ during the first 3 months of life, breast feeding duration, signs of moderate/ extensive mould at home visit (6 or 12 months) and distance $(\leq 150 \mathrm{~m})$ from a highway (6 or 12 months). Season of birth corresponds generally to other potential exposures that might play a causal role in respiratory disease (see online supplementary methods).

Potential selection bias due to exclusion from final models of children with missing outcome data or missing covariates was addressed by comparing our results with GLM models that included stabilised inverse probability weights ${ }^{25} 26$ (see online supplementary material).

We analysed the data using Stata (V.IC13.0; StataCorp, College Station, Texas, USA) for GLM models and R (V.2.14.2; R Foundation for Statistical Computing, Vienna, Austria) for Super Learner models. We set statistical significance at $\mathrm{p}<0.05$ for all analyses. We defined borderline significance at $0.05<\mathrm{p}<0.1$.

\section{RESULTS}

Most cohort participants were born to Mexican immigrant mothers who had less than a high school education. Most mothers lived in a household with at least one farm worker and almost $40 \%$ reported food insecurity when the children were 7 years old (table 1). Mean $\pm \mathrm{SD}$ values of $\mathrm{FEV}_{1}(\mathrm{~L} / \mathrm{s}), \mathrm{FVC}(\mathrm{L}), \mathrm{FEV}_{1} \mathrm{FVC}$ ratio and $\mathrm{FEF}_{25-75}(\mathrm{~L} / \mathrm{s})$ were $1.70 \pm 0.46,1.97 \pm 0.51,0.89 \pm 0.06$ and $2.29 \pm 0.82$, respectively (table 2 ). The geometric means of specific gravity-adjusted total DAP, DE and DM concentrations during pregnancy were 145, 22 and $105 \mathrm{nmol} / \mathrm{L}$, respectively. Child creatinine-adjusted total DAP concentrations decreased with age, averaging 229, 237, 214, 161 and $128 \mathrm{nmol} / \mathrm{g}$ creatinine at $0.5,1,2,3.5$ and 5 years of age, respectively (see online supplementary material and table E1).

Average DAP urinary concentrations in mothers during pregnancy were not significantly associated with lung function measurements (see online supplementary table E2). Estimates from models from the first and second half of pregnancy and from models that also included children who had only one lung function measurement were also non-significant (data not shown).

We found adverse associations, between the AUC of total DAPs, DEs and DMs concentrations measured in children's urine between 0.5 and 5 years old and $\mathrm{FEV}_{1}, \mathrm{FVC}$ and $\mathrm{FEF}_{25-75}$ measured at age 7 (table 3). Specifically, the highest $\mathrm{FEV}_{1}$ measured from children who had at least two acceptable manoeuvres was significantly associated with total DAPs (adjusted $B$ for a 10 -fold increase in concentration $(a ß)=-0.16$, 95\% CI
Table 1 Maternal and child characteristics, Center for the Health Assessment of Mothers and Children of Salinas (CHAMACOS), CA, 1999-2000 ( $\mathrm{n}=279)$

\begin{tabular}{|c|c|c|}
\hline Characteristics & $\mathbf{n}$ & $\%$ \\
\hline \multicolumn{3}{|l|}{ Child's sex } \\
\hline Boys & 129 & 46.2 \\
\hline Girls & 150 & 53.8 \\
\hline \multicolumn{3}{|l|}{ Season of birth* } \\
\hline Mould & 105 & 37.6 \\
\hline Wet & 53 & 19.0 \\
\hline Pollen & 58 & 20.8 \\
\hline Dry & 63 & 22.6 \\
\hline \multicolumn{3}{|l|}{ Breast feeding duration } \\
\hline Never breastfed & 13 & 4.7 \\
\hline$\leq 6$ Months & 128 & 45.9 \\
\hline$>6$ Months & 138 & 49.5 \\
\hline \multicolumn{3}{|l|}{ Mother's country of birth } \\
\hline Mexico & 237 & 84.9 \\
\hline USA/other & 42 & 15.1 \\
\hline \multicolumn{3}{|l|}{ Maternal education } \\
\hline$\leq 6$ th Grade & 123 & 44.1 \\
\hline 7-12th Grade & 97 & 34.8 \\
\hline Completed high school & 59 & 21.1 \\
\hline \multicolumn{3}{|l|}{ Maternal history of asthma } \\
\hline Yes & 10 & 3.6 \\
\hline No & 268 & 96.4 \\
\hline \multicolumn{3}{|l|}{ Mother smoked during pregnancy } \\
\hline Yes & 12 & 4.3 \\
\hline No & 267 & 95.7 \\
\hline \multicolumn{3}{|c|}{ Home $\leq 150 \mathrm{~m}$ from highway 101 (6 or 12 months) } \\
\hline Yes & 14 & 5.3 \\
\hline No & 251 & 94.7 \\
\hline \multicolumn{3}{|l|}{ Mean daily $\mathrm{PM}_{2.5}$ near home (0-3 months) } \\
\hline$<8 \mu \mathrm{g} / \mathrm{m}^{3}$ & 126 & 45.2 \\
\hline $8-12 \mu \mathrm{g} / \mathrm{m}^{3}$ & 121 & 43.4 \\
\hline$\geq 12 \mu \mathrm{g} / \mathrm{m}^{3}$ & 32 & 11.5 \\
\hline \multicolumn{3}{|c|}{ Signs of moderate/extensive mould at home visit ( 6 or 12 months) } \\
\hline Yes & 183 & 69.1 \\
\hline No & 82 & 30.9 \\
\hline \multicolumn{3}{|l|}{ Pets at home at ages $5-7$} \\
\hline Yes & 42 & 15.1 \\
\hline No & 237 & 84.9 \\
\hline \multicolumn{3}{|c|}{ Agricultural workers in the household at age 7} \\
\hline Yes & 187 & 67.0 \\
\hline No & 92 & 33.0 \\
\hline \multicolumn{3}{|l|}{ Food insecurity status at age 7} \\
\hline Food secure & 174 & 62.4 \\
\hline Food insecure with or without hunger & 105 & 37.6 \\
\hline \multicolumn{3}{|c|}{$\begin{array}{l}\text { *Season of birth corresponds generally to other potential exposures that might play a } \\
\text { causal role in respiratory disease. We defined the seasons as follows: pollen } \\
\text { (mid-January to mid-May 2000), dry (mid-May to mid-August 2000), mould } \\
\text { (mid-August to mid-January 2001), wet (mid-January to mid-March 2001), pollen } \\
\text { (mid-March to mid-May 2001) and dry (mid-May to October 2001). Differences in the } \\
\text { date of seasons across years are based on actual rainfall and measured pollen counts } \\
\text { for that year. }\end{array}$} \\
\hline
\end{tabular}

-0.30 to $-0.02, \mathrm{p}=0.03)$ and DEs $((\mathrm{a} \beta)=-0.16,95 \% \mathrm{CI}-0.30$ to $-0.03, \mathrm{p}=0.02)$ and borderline associated with $\mathrm{DMs}(\mathrm{a} \beta=$ $-0.12,95 \%$ CI -0.25 to $0.02, p=0.08$ ) (table 3 ). The highest FVC measured from children who had at least two acceptable manoeuvres was borderline associated with total DAPs $(\mathrm{a} ß=$ $-0.17,95 \%$ CI -0.34 to $0.01, p=0.06)$ and DEs $(a ß=-0.17$, 
Table 2 Lung function measurements at age $7^{*} \dagger$, Center for the Health Assessment of Mothers and Children of Salinas (CHAMACOS) birth cohort, Salinas Valley, CA, 1999-2000 ( $n=279)$

\begin{tabular}{lrl}
\hline Variable & \multicolumn{1}{c}{ Mean \pm SD } & $\mathbf{n}$ \\
\hline $\mathrm{FEV}_{1}(\mathrm{~L} / \mathrm{s})$ & $1.70 \pm 0.46$ & 279 \\
$\mathrm{FVC}(\mathrm{L})$ & $1.97 \pm 0.51$ & 250 \\
$\mathrm{FEV}_{1} / \mathrm{FVC}$ & $0.89 \pm 0.06$ & 250 \\
$\mathrm{FEF}_{25-75}(\mathrm{~L} / \mathrm{s})$ & $2.29 \pm 0.82$ & 250 \\
Height $(\mathrm{cm})_{\text {Weight }(\mathrm{kg})}^{123.56 \pm 5.66}$ & 279 \\
Age (years) & $29.42 \pm 7.53$ & 279 \\
\hline
\end{tabular}

${ }^{*}$ Average values.

†ldentical dry-seal spirometers were used in the study. Routine calibration was conducted every morning. Three identical EASYONE spirometers were used by two technicians; $92 \%$ of tests were performed by the same technician. Each child performed a maximum of eight expiratory manoeuvres and up to three best acceptable tests were kept by the spirometric software.

$95 \% \mathrm{CI}-0.33$ to $0.00, \mathrm{p}=0.06)$ and non-significantly associated with DMs $(\mathrm{a} ß=-0.13,95 \% \mathrm{CI}-0.29$ to $0.04, \mathrm{p}=0.1)$ (table 3). Additionally, the highest $\mathrm{FEF}_{25-75}$ measured from children that had at least two acceptable manoeuvres was borderline associated with DEs $(\mathrm{a} \beta=-0.26,95 \%$ CI -0.55 to 0.03 , $\mathrm{p}=0.08$ ) (table 3 ) and was not significantly associated with total DAPs or DMs. The $\mathrm{FEV}_{1} / \mathrm{FVC}$ ratio was not associated with any DAP measurement (table 4).

Similar results were obtained when we excluded children who had been prescribed medication for asthma, wheezing or tightness in the chest during the past 12 months and who had used any medication in the past $24 \mathrm{~h}$ before spirometry (see online supplementary tables E3, E6 and E7). Results were also similar when we included in the models children who had one, two or three acceptable manoeuvres and when we conducted minimally adjusted models (tables 3 and 4, see online supplementary tables E2-E7). Similar results were obtained when we did not adjust maternal DAP concentrations for specific gravity or child AUC levels for creatinine (data not shown). When we examined sex interactions in our models, we found no interaction by sex ( $p$ value for interaction: 0.3 to 0.6 ; data not shown). Estimates for both inverse probability weighted and unweighted regression models yielded similar results (data not shown), suggesting that selection bias did not substantially modify our results. The attributes of families included in this analysis $(n=279)$ did not differ significantly from those of families not included, including urinary DAP concentrations during childhood, maternal asthma, maternal education, marital status, poverty category and child's birth weight. However, mothers of children included in this study were slightly older (mean age 26.5 vs $25.4, p=0.02$ ) and breastfed the index child for longer (9.1 months vs 4.9, $\mathrm{p}<0.01$ ) than those from the initial cohort (see online supplementary methods).

\section{DISCUSSION}

Although organophosphate pesticides are still widely used in modern agriculture, ${ }^{4}$ the effects of low-level exposure on lung function of residents living in agricultural communities have not been previously well studied. ${ }^{3}$ Our study provides the first evidence for an adverse association between exposure to OPs during childhood and pulmonary function of children. We assessed this relationship using a biomarker of exposure, urinary DAP metabolites, measured during the prenatal period and multiple times during childhood, in a prospective birth cohort design. Our findings support and extend the results of previous occupational studies of OP exposure and respiratory symptoms and function, ${ }^{3}$ case studies of paediatric OP poisonings ${ }^{27}$ and cross-sectional investigations of respiratory symptoms in adults and children following reported pesticide exposure. ${ }^{15-19}$ Our findings on pulmonary function support our previous analysis of an association between childhood DAPs and maternal report of child's respiratory symptoms, ${ }^{20}$ but unlike our previous study on symptoms, we found no association between in utero exposure and pulmonary function.

It is biologically plausible that chronic exposure to OPs might result in abnormalities of the lung. In contrast to the wellknown acute respiratory effects of high-dose OP exposure, which include bronchoconstriction, pulmonary oedema and respiratory muscle paralysis, ${ }^{28}$ the chronic effects of low-dose OP exposure are less well understood. Recently, it has been reported that additional mechanisms, including inhibition of muscarinic receptors in the airways, may mediate effects of

Table 3 Associations ${ }^{*} \dagger(\beta(95 \% \mathrm{CI}))$ of lung function at age 7 with childhood concentrations of dialkyl phosphate (DAP) metabolitesł measured at follow-up visits between 0.5 and 5 years of age

\begin{tabular}{|c|c|c|c|c|c|c|}
\hline $\mathbf{n}$ & DEs & p Value & DMs & p Value & Total DAPs & p Value \\
\hline \multicolumn{7}{|c|}{ Highest $\mathrm{FEV}_{1}$ for children who had one, two, or three manoeuvres } \\
\hline 224 & $-0.18(-0.32$ to -0.05$)$ & 0.009 & $-0.10(-0.23$ to 0.04$)$ & 0.1 & $-0.14(-0.29$ to 0.00$)$ & 0.05 \\
\hline \multicolumn{7}{|c|}{ Highest $\mathrm{FEV}_{1}$ for children who had at least two manoeuvres } \\
\hline 207 & $-0.16(-0.30$ to -0.03$)$ & 0.02 & $-0.12(-0.25$ to 0.02$)$ & 0.08 & $-0.16(-0.30$ to -0.02$)$ & 0.03 \\
\hline \multicolumn{7}{|c|}{ Highest FVC for children who had one, two, or three manoeuvres } \\
\hline 203 & $-0.18(-0.34$ to -0.02$)$ & 0.03 & $-0.08(-0.24$ to 0.09$)$ & 0.4 & $-0.12(-0.29$ to 0.05$)$ & 0.2 \\
\hline \multicolumn{7}{|c|}{ Highest FVC for children who had at least two manoeuvres } \\
\hline 175 & $-0.17(-0.33$ to 0.00$)$ & 0.06 & $-0.13(-0.29$ to 0.04$)$ & 0.1 & $-0.17(-0.34$ to 0.01$)$ & 0.06 \\
\hline \multicolumn{7}{|c|}{ Highest $\mathrm{FEF}_{25-75}$ for children who had one, two or three manoeuvres } \\
\hline 203 & $-0.36(-0.64$ to -0.08$)$ & 0.01 & $-0.09(-0.37$ to 0.20$)$ & 0.6 & $-0.18(-0.49$ to 0.12$)$ & 0.2 \\
\hline \multicolumn{7}{|c|}{ Highest $\mathrm{FEF}_{25-75}$ for children who had at least two manoeuvres } \\
\hline 175 & $-0.26(-0.55$ to 0.03$)$ & 0.08 & $-0.06(-0.34$ to 0.23$)$ & 0.7 & $-0.14(-0.44$ to 0.17$)$ & 0.4 \\
\hline
\end{tabular}

${ }^{*}$ Coefficients reflect change per 10 -fold increase in creatinine-adjusted (nmol/g creatinine) metabolite concentrations assessed by the area under the curve.

†Adjusted for child's sex, age, age squared, log height, maternal smoking during pregnancy, season of birth (mould/wet/pollen/dry), mean daily PM 2.5 during the first 3 months of life breast feeding duration, signs of moderate/extensive mould at home visit ( 6 or 12 months), distance ( $\leq 150 \mathrm{~m})$ from highway (6 or 12 months), pets at home (5-7 years), household food insecurity score (7 years), maternal education, season of spirometry and technician.

‡Diethyl (DE) phosphate, dimethyl (DM) phosphate and total dialkyl phosphate (DAP) metabolites. 
Table 4 Associations* $\dagger(\beta(95 \% \mathrm{Cl}))$ of $\mathrm{FEV}_{1} / \mathrm{FVC}$ ratio at age 7 with childhood concentrations of dialkyl phosphate (DAP) metabolitesł measured at follow-up visits between 0.5 and 5 years of age

\begin{tabular}{|c|c|c|c|c|c|c|}
\hline $\mathbf{n}$ & DEs & p Value & DMs & p Value & Total DAPs & p Value \\
\hline \multicolumn{7}{|c|}{ Highest $\mathrm{FEV}_{1} / \mathrm{FVC}$ ratio for children who had one, two, or three manoeuvres } \\
\hline 203 & $0.00(-0.02$ to 0.01$)$ & 0.7 & $0.01(-0.01$ to 0.02$)$ & 0.6 & $0.00(-0.02$ to 0.02$)$ & 0.8 \\
\hline \multicolumn{7}{|c|}{ Highest $\mathrm{FEV}_{1} / \mathrm{FVC}$ ratio for children who had at least two manoeuvres } \\
\hline 175 & $-0.01(-0.03$ to 0.01$)$ & 0.5 & $0.01(-0.01$ to 0.03$)$ & 0.4 & $0.01(-0.02$ to 0.03$)$ & 0.6 \\
\hline
\end{tabular}

chronic exposure to OPs at environmental relevant concentrations-below those needed to inhibit AChE. ${ }^{8}$ However, more studies are needed to clarify the underlying mechanisms between chronic OP exposure and lung impairment.

Furthermore, because both $\mathrm{FEV}_{1}$ and FVC were associated with DAP levels, while the $\mathrm{FEV}_{1} \mathrm{FVC}$ ratio was not $(0.3 \leq \mathrm{p} \leq 0.9)$, we suggest that prolonged OP exposure may restrict the growth of lung function. Although some occupational studies have reported either a potentially obstructive ${ }^{29}$ or no effect ${ }^{30}$ of OP exposure, other studies suggest that a restrictive abnormality may be associated with occupational exposure to OPs. ${ }^{14} 3132$ For example, Peiris-John et al ${ }^{14}$ reported an association of AChE levels between and during OP spraying seasons, and a reduction of $\mathrm{FEV}_{1}$ and FVC with a normal $\mathrm{FEV}_{1} \mathrm{FVC}$ ratio among 25 farmers occupationally exposed to OPs. However, our results for $\mathrm{FVC}$ and the $\mathrm{FEV}_{1} \mathrm{FVC}$ ratio should be interpreted with caution since collecting high-quality spirometric data function is particularly challenging in young children. $^{33}$

Limitations of the study design include loss to follow-up and challenges in exposure assessment. Selection bias due to loss to follow-up is always a possible limitation in observational studies. However, the results of the sensitivity analysis we conducted imply that selection bias did not substantially modify our results. There are no long-term biomarkers of OP pesticide exposure. The available methods have several limitations, including a short half-life in the body, high variability in exposure and being classspecific rather than pesticide-specific. ${ }^{3} 34$ Owing to logistical challenges, we also used spot urine samples, which may be less representative of exposure than $24 \mathrm{~h}$ samples. However, we did previously find strong correlations between full-day $24 \mathrm{~h}$ samples and same-day spot samples. ${ }^{34}$ Finally, urinary DAPs may represent exposure to preformed metabolites in food or the environment and not direct exposure to parent compounds. ${ }^{35}$ Thus, our use of seven measurements collected from pregnancy to early childhood might have resulted in some exposure misclassification. Nevertheless, DAPs are commonly used in epidemiological investigations and they represent the current state-of-the-art method for assessing broad exposure to OPs, ${ }^{35} 36$ since there are few sensitive and specific assays for parent compounds in blood or pesticide-specific metabolites in urine. Moreover, any exposure misclassification, if it occurred, would have tended to bias our results towards the null hypothesis.

Strengths of our study include the prospective cohort design with a relatively large sample size; an objectively measured outcome, pulmonary function; and the use of a biomarker for OP exposure. Additionally, we used a biomarker that was measured twice in pregnancy and five times during early childhood, which allowed us to study the long-term effects that OPs might have on respiratory health. Moreover, the temporal sequence between OP exposure, measured during pregnancy and at ages 0.5-5 years of age and lung function, measured at age 7 , allowed us to eliminate the potential for temporal bias.

In conclusion, our findings suggest that early-childhood exposure to OP pesticides is associated with decreased pulmonary function among school-age children living in an agricultural community in California. In our study, each 10 -fold increase in concentrations of OP metabolites measured through early childhood (0.5-5 years of age) was associated with a $159 \mathrm{~mL} / \mathrm{s}$ decrease in $\mathrm{FEV}_{1}$ in 7-year-old children. In comparison, 30 years ago, passive paediatric exposure to maternal cigarette smoke was found to be associated with a decrease in $\mathrm{FEV}_{1}$ of $101 \mathrm{~mL} / \mathrm{s}$ after 5 years of exposure. ${ }^{1}$ Thus, this study adds exposure to OP pesticides to the growing list of environmental exposures, including air pollution, indoor cook stove smoke and environmental tobacco smoke, ${ }^{12}$ that may play a key role in the pathophysiology of chronic respiratory disease in children. We suggest that future studies should attempt to replicate our findings in different study populations and focus on the mechanisms by which OP exposure affects lung development and function. Given the widespread use of OP pesticides worldwide, we believe these findings deserve further attention.

Acknowledgements We thank the CHAMACOS staff, students, community partners and participants and families, without whom this study would not have been possible. We especially thank Michelle Vedar, MPH, the CHAMACOS field office staff as well as Nina Holland, PhD and the staff of the UC Berkeley School of Public Health Biorepository for their assistance in specimen management, and Dana Barr, PhD and her staff at CDC for DAP measurements.

Contributors RR: carried out the scientific literature search; analysed the data; prepared the tables; drafted the manuscript; $B E, K G H$ and $A B$ collected the data; RR, $B E$, JRB and KGH interpreted the data; $B E, J R B, K G H, R B G, S M$ and $A B$ provided critical revisions. All authors provided substantial contribution to the conception/ design of work; approved the current version and state that it is ready to be published; and agree to be accountable for all aspects of the work in ensuring that questions related to the accuracy or integrity of any part of the work are appropriately investigated and resolved.

Funding This work was supported by the grants 2P01ES009605 from NIEHS and RD-82670901, RD-83171001 and RD-83451301 from the U.S. EPA (B.E., PI) and by a post-doctoral fellowship from the Environment and Health Fund (EHF), Jerusalem, Israel (RR). The contents of this article are solely the responsibility of the authors and do not necessarily represent the official views of the funders.

Competing interests $A B$ has served as a consultant on cases unrelated to the topics covered in this paper and has participated as a member of the Board for The Organic Center, a non-profit organisation that provides information for scientific research about organic food and farming. JRB is the physician member of the California Air Resources Board, a paid position.

\section{Patient consent Obtained.}

Ethics approval Research protocols were approved by the University of California, Berkeley, Committee for the Protection of Human Subjects.

Provenance and peer review Not commissioned; externally peer reviewed. 


\section{REFERENCES}

1 Tager IB, Weiss ST, Muñoz A, et al. Longitudinal study of the effects of maternal smoking on pulmonary function in children. N Engl J Med 1983;309:699-703.

2 Franklin P, Kusel M. Environmental contributions to childhood asthma. J Environ Immunol Toxicol 2013;1:53-7.

3 Amaral AF. Pesticides and asthma: challenges for epidemiology. Front Public Health 2014;2:6.

4 Grube A, Donaldson D, Kiely T, et al. Pesticides industry sales and usage: 2006 and 2007 market estimates. Environmental Protection Agency, US, Office of Chemical Safety and Pollution Prevention, 2011. http://www.epa.gov/opp00001/pestsales/ 07pestsales/market_estimates2007.pdf (accessed 4 Nov 2014).

5 Pesticide registration status for Organophosphates, U.S. EPA (U.S. Environmental Protection Agency), 2013. http://www.epa.gov/oppsrrd1/reregistration/status_op. htm. (accessed 4 Nov 2014).

6 CDC (Centers for Disease Control and Prevention). Fourth Report on Human Exposure to Environmental Chemicals, Updated Tables, (July, 2014). Atlanta, GA U.S. Department of Health and Human Services, Centers for Disease Control and Prevention, 2014. http://www.cdc.gov/exposurereport/ (accessed 4 Nov 2014).

7 Barnes PJ. Neural control of human airways in health and disease. Am Rev Respir Dis 1986;134:1289-314.

8 Fryer AD, Lein PJ, Howard AS, et al. Mechanisms of organophosphate insecticide-induced airway hyperreactivity. Am J Physiol Lung Cell Mol Physiol 2004;286:963-9.

9 Mamane A, Baldi I, Tessier JF, et al. Occupational exposure to pesticides and respiratory health. Eur Respir Rev 2015;24:306-19.

10 Hoppin JA, Umbach DM, London SJ, et al. Pesticides and adult respiratory outcomes in the agricultural health study. Ann N Y Acad Sci 2006;1076:343-54.

11 Hernández AF, Parrón T, Alarcón R. Pesticides and asthma. Curr Opin Allergy Clin Immunol 2011;11:90-6.

12 Zock JP, Sunyer J, Kogevinas M, et al. Occupation, chronic bronchitis and lung function in young adults: an international study. Am J Respir Crit Care Med 2001;163:1572-7.

13 de Jong K, Boezen HM, Kromhout $\mathrm{H}$, et al. Pesticides and other occupational exposures are associated with airway obstruction: the LifeLines cohort study. Occup Environ Med 2014;71:88-96.

14 Peiris-John RJ, Ruberu DK, Wickremasinghe AR, et al. Low-level exposure to organophosphate pesticides leads to restrictive lung dysfunction. Respir Med 2005;99:1319-24.

15 Nriagu J, Robins T, Gary L, et al. Prevalence of asthma and respiratory symptoms in south-central Durban, South Africa. Eur J Epidemiol 1999;15:747-55.

16 Yemaneberhan $\mathrm{H}$, Bekele $\mathrm{Z}$, Venn $\mathrm{A}$, et al. Prevalence of wheeze and asthma and relation to atopy in urban and rural Ethiopia. Lancet 1997;350:85-90.

17 Salameh P, Baldi I, Brochard P, et al. Respiratory symptoms in children and exposure to pesticides. Eur Respir J 2003;22:507-12.

18 Salam MT, Li YF, Langholz B, et al. Early-life environmental risk factors for asthma: findings from the Children's Health Study. Environ Health Perspect 2004:112:760-5
19 Xu X, Nembhard WN, Kan H, et al. Residential pesticide use is associated with children's respiratory symptoms. J Occup Environ Med 2012;54:1281-7.

20 Raanan R, Harley KG, Balmes JR, et al. Early-life exposure to organophosphate pesticides and pediatric respiratory symptoms in the CHAMACOS cohort. Environ Health Perspect 2015;123:179-85.

21 Eskenazi B, Marks AR, Bradman A, et al. In utero exposure to dichlorodiphenyltrichloroethane (DDT) and dichlorodiphenyldichloroethylene (DDE) and neurodevelopment among young Mexican American children. Pediatrics 2006;118:233-41.

22 Bradman A, Eskenazi B, Barr DB, et al. Organophosphate urinary metabolite levels during pregnancy and after delivery in women living in an agricultural community. Environ Health Perspect 2005;113:1802-7.

23 Bravo R, Driskell WJ, Whitehead RD, et al. Quantitation of dialkyl phosphate metabolites of organophosphate pesticides in human urine using GC-MS-MS with isotopic internal standards. J Anal Toxicol 2002;26:245-52.

24 Harrison GG, Stormer A, Herman DR, et al. Development of a spanish-language version of the U.S. household food security survey module. J Nutr 2003;133:1192-7.

25 Hernan MA, Hernandez-Diaz S, Robins JM. A structural approach to selection bias. Epidemiology 2004;15:615-25.

26 van der Laan MJ, Polley EC, Hubbard AE. Super Learner. UC Berkeley Division of Biostatistics Working Paper Series 2007. Working Paper 222. http://biostats.bepress. com/ucbbiostat/paper22

27 Cavari Y, Lifshitz M, Leibson T, et al. Severe and uncommon complications of anticholinesterase intoxication in children. Harefuah 2013:152:391-4.

28 Carey JL, Dunn C, Gaspari RJ. Central respiratory failure during acute organophosphate poisoning. Respir Physiol Neurobiol 2013;189:403-10.

29 Salameh P, Waked M, Baldi I, et al. Spirometric changes following the use of pesticides. East Mediterr Health J 2005;11:126.

30 Fieten $\mathrm{KB}$, Kromhout $\mathrm{H}$, Heederik $\mathrm{D}$, et al. Pesticide exposure and respiratory health of indigenous women in Costa Rica. Am J Epidemiol 2009;169:1500-6.

31 Rastogi SK, Gupta BN, Husain T, et al. Study of respiratory impairment among pesticide sprayers in Mango plantations. Am J Ind Med 1989;16:529-38.

32 Chakraborty S, Mukherjee S, Roychoudhury S, et al. Chronic exposures to cholinesterase-inhibiting pesticides adversely affect respiratory health of agricultural workers in India. J Occup Health 2009;51:488-97.

33 Hall GL, Brookes IM. Techniques for the measurement of lung function in toddlers and preschool children. In: Hammer J, Eber E, eds. Paediatric Pulmonary Function Testing. Basel: Karger Publishers. 2005:66-77.

34 Bradman A, Kogut K, Eisen EA, et al. Variability of organophosphorous pesticide metabolite levels in spot and 24-hr urine samples collected from young children during 1 week. Environ Health Perspect 2013;121:118-24.

35 Sudakin DL, Stone DL. Dialkyl phosphates as biomarkers of organophosphates: the current divide between epidemiology and clinical toxicology. Clin Toxicol (Phila) 2011;49:771-81

36 Chen L, Zhao T, Pan C, et al. Preformed biomarkers including dialkylphosphates (DAPs) in produce may confound biomonitoring in pesticide exposure and risk assessment. J Agric Food Chem 2012;60:9342-51. 